Research Article

\title{
Abdominal tuberculosis: an epidemiological profile and management of 40 cases in a tertiary set up
}

\author{
Kiran Arjun Urabinahatti*, Atul Kumar Singh, Ashok Nayak, Rachna Gupta, Mayank Jain, \\ Chandrashekar Dubey, Rishi Kumar Garg
}

Department of Surgery, SS Medical College, Rewa, MP, India

Received: 12 May 2016

Accepted: 11 June 2016

*Correspondence:
Dr. Kiran Arjun Urabinahatti,
E-mail: kiran.jnmc@gmail.com

Copyright: ( ) the author(s), publisher and licensee Medip Academy. This is an open-access article distributed under the terms of the Creative Commons Attribution Non-Commercial License, which permits unrestricted non-commercial use, distribution, and reproduction in any medium, provided the original work is properly cited.

\begin{abstract}
Background: Tuberculosis is the most important communicable disease world-wide. It is an important cause of morbidity in India. Abdominal tuberculosis mimicks most abdominal diseases and hence is a difficult diagnosis. This study aims to document the epidemiological profile and management strategies of abdominal tuberculosis according to various sites and surgical pathology.

Methods: Forty new cases of abdominal tuberculosis were diagnosed and treated over a period of one year (20142015) in surgical wards of Shyam Shah Medical College and associated Sanjay Gandhi Memorial Hospital, Rewa (M.P). The patients were selected after they were diagnosed as abdominal tuberculosis on the basis of clinical history, thorough clinical examination and clinical picture during surgery. Further diagnosis was confirmed by histopathology and tissue culture studies. All the patients diagnosed with abdominal tuberculosis, were put on ATT for a period of 6 month, and they were asked to present themselves for follow up at regular intervals.

Results: Out of 40 patients with abdominal tuberculosis, 26 were males (65\%) and $14(35 \%)$ were females. male to female ratio was 1.8:1. Adults in their 3rd decade (37.5\%) and 4th decade (22.5\%) were most commonly affected. Pain abdomen was the most common presenting complaint present in $82.5 \%$ cases. Abdomen distension was the most common sign (75\%). Pulmonary tuberculosis was associated with in $22.5 \%$ cases. $5 \%$ cases of abdominal tuberculosis were co infected with HIV infection. 55\% cases underwent surgical management followed by ATT, and 45\% cases needed only ATT as treatment. In cases explored surgically, ulcero sclerotic type (ileal stricture with perforation) was the most common pathology seen in $31.8 \%$ cases. Ileocecal region was the most common site of involvement with $67.3 \%$ occurrence. Mortality rate was $5 \%$.

Conclusions: Abdominal tuberculosis is predominantly seen in low socio economic group. Adults in their 3rd and 4th decades are most commonly affected, which is the earning age group and hence can have economic implications. Majority of cases were of primary intestinal type and in some it was secondary to pulmonary tuberculosis. Majority of cases underwent surgical management followed by ATT. Anti tuberculosis therapy is still the treatment of choice in abdominal tuberculosis and surgery is only indicated in various complication of abdominal tuberculosis.
\end{abstract}

Keywords: Anti tubercular therapy, HIV, Ileostomy, Sub acute intestinal obstruction

\section{INTRODUCTION}

Tuberculosis continues to be prevalent in the underdeveloped and developing third world, and although it was on the verge of eradication in the developed world, its prevalence is increasing there too, due to factors such as trans global immigration, ageing populations, alcoholism, socio-economic deprivation, and more recently, acquired immunodeficiency syndrome (AIDS). Tuberculosis (TB) can involve any part of the gastrointestinal tract from mouth to anus, the peritoneum and the pancreatobiliary system. Both the incidence and 
the severity of abdominal tuberculosis are expected to increase with increasing incidence of HIV infection in India. In a study from Mumbai, HIV seroprevalence was found in 16.6 per cent in patients with abdominal tuberculosis as compared to 1.4 percent in voluntary blood donors. ${ }^{1}$

TB of the gastrointestinal tract is the sixth most frequent form of extra-pulmonary site, after lymphatic, genitourinary, bone and joint, miliary and meningeal tuberculosis. Abdominal tuberculosis can affect the gastro intestinal tract; peritoneum lymph nodes or the solid viscera including pancreas, spleen and occasionally pancreas. The symptom of abdominal tuberculosis is generally vague and non-specific. It may mimic any intra-abdominal disease and can challenge the diagnostic skills. Tuberculosis of the Ileocaecal region ranks first in incidence among intestinal / abdominal tuberculosis. ${ }^{2}$

Mortality rate has come down to $6 \%$ from $20-50 \%$ after introduction of anti-tubercular chemotherapy. ${ }^{3}$ Surgical management of abdominal tuberculosis (intestinal tuberculosis) has changed considerably from bypass operations, hemicolectomy to conservative resection and stricturoplasty. The aim of surgery in case of intestinal tuberculosis is to overcome deleterious effect of the disease like tissue disorganization, obstruction and perforation.

\section{METHODS}

This prospective study was conducted in patients who were admitted in department of surgery, Shyam Shah Medical College and associated Sanjay Gandhi Memorial Hospital, Rewa, M.P during August 2014-July 2015.

This study includes selection of patients with Abdomen tuberculosis on a prospective basis. Patients admitted through OPD, casualty and transferred in from other departments were all included in the study. Patients presenting with chronic abdominal pain, chronic diarrhoea and weight loss, HIV patient with chronic pain abdomen and patients presenting with surgical complications such as lump in abdomen, intestinal obstruction, perforation and ascitis, are included in this study.

On admission the detail profile of patient were noted including age, sex, religion, socio economic status. Detailed clinical history was taken and patients examined thoroughly. Patients were specially enquired about history of pulmonary tuberculosis in past or history of exposure among family. Patients who presented with acute symptoms and signs including cases of peritonitis and acute intestinal obstruction were resuscitated primarily and emergency laparotomy was done. In cases presenting with sub acute obstruction, initial wait and watch policy was observed and patients who did not improve were operated selectively. In all the cases explored, intra operative findings were noted and biopsy was taken for histopathological study. Patients who presented with lump abdomen, ascitis, and other acute or chronic abdominal complaints were exhaustively investigated further with X-ray abdomen, ultrasound of abdomen, CT scan, ascitic fluid examination and molecular tests like gene expert. In all patients suspected of abdominal tuberculosis, supportive investigations like complete blood count, ESR, chest X-ray and HIV serology was done and recorded. In operated cases, immediate complication and late complications were noted during hospital stay and follow up.

Forty patients were selected after they were diagnosed as abdominal tuberculosis on the basis of clinical history, physical examination: routine investigations and supportive investigation like X-ray abdomen, USG, CT abdomen, and biopsies.

All the patients diagnosed with abdominal tuberculosis, were put on ATT for a period of 6 month under category 1 DOTS of RNTPC as per recent guidelines, and they were asked to present themselves for follow up at regular intervals. Most of the patient had uneventful recovery but some cases had post operative complications like wound dehiscence, faecal fistula and mortality due to late medical advice and presentation in terminal stage.

\section{RESULTS}

Forty cases of abdominal tuberculosis were diagnosed out of 8289 admissions, which accounted for admission rate of $0.48 \%$ and male to female ratio was $1.8: 1$.

Table 1: Distribution according to age.

\begin{tabular}{|lll|}
\hline Age in years & No of cases & Percent \\
\hline Below 20 & 04 & 10 \\
\hline $21-30$ & 15 & 37.5 \\
\hline $31-40$ & 09 & 22.5 \\
\hline $41-50$ & 04 & 10 \\
\hline $51-60$ & 04 & 10 \\
\hline Above 60 & 04 & 10 \\
\hline Total & $\mathbf{4 0}$ & $\mathbf{1 0 0}$ \\
\hline
\end{tabular}

Table 2: Distribution according to sex.

\begin{tabular}{|lll|}
\hline Sex & No of cases & Percent \\
\hline Male & 26 & 65 \\
\hline Female & 14 & 35 \\
\hline Total & $\mathbf{4 0}$ & $\mathbf{1 0 0}$ \\
\hline
\end{tabular}

Table 3: Distribution according to socio economic status (SES).

\begin{tabular}{|lll|}
\hline SES & No of cases & Percent \\
\hline Below poverty (BPL) & 34 & 85 \\
\hline Above poverty (APL) & 06 & 15 \\
\hline Total & $\mathbf{4 0}$ & $\mathbf{1 0 0}$ \\
\hline
\end{tabular}


Table 4: Distribution of cases according to symptoms $(n=40)$.

\begin{tabular}{|lll|}
\hline Symptom & No of cases & Percent \\
\hline Pain abdomen & 33 & 82.5 \\
\hline Abdomen distension & 26 & 62.5 \\
\hline Bowel disturbance & 21 & 52.5 \\
\hline Weight loss & 20 & 50 \\
\hline Fever & 19 & 47.5 \\
\hline Vomiting & 08 & 20 \\
\hline Lump abdomen & 06 & 15 \\
\hline
\end{tabular}

Table 5: Distribution according to signs.

\begin{tabular}{|lll|}
\hline Sign & No of cases & Percent \\
\hline Distension & 30 & 75 \\
\hline Tenderness & 23 & 57.5 \\
\hline Free fluid & 17 & 42.5 \\
\hline Lump & 07 & 17.5 \\
\hline Guarding/rigidity & 03 & 7.5 \\
\hline Visible peristalsis & 01 & 2.5 \\
\hline
\end{tabular}

According to clinical presentation, patients were categorized into acute, sub acute and chronic groups. These include:

a) Acute: perforation peritonitis and acute intestinal obstruction.

b) Sub acute: sub acute obstruction and lump in abdomen.

c) Chronic: ascitis and chronic obstruction with or without lump.

Table 6: Distribution according to type of presentation.

\begin{tabular}{|lll|}
\hline Presentation & No of cases & Percent \\
\hline Acute & 08 & 20 \\
\hline Sub-acute & 22 & 55 \\
\hline Chronic & 10 & 25 \\
\hline Total & $\mathbf{4 0}$ & $\mathbf{1 0 0}$ \\
\hline
\end{tabular}

Table 7: Distribution according to hemoglobin (Hb) levels.

\begin{tabular}{|llllll|}
\hline Hb & \multicolumn{7}{c|}{ ESR } \\
\hline Category & $\begin{array}{l}\text { No of } \\
\text { cases }\end{array}$ & $\%$ & Category & $\begin{array}{l}\text { No of } \\
\text { cases }\end{array}$ & $\%$ \\
\hline $\begin{array}{l}\text { Below } 10 \\
\text { gm\% }\end{array}$ & 22 & 55 & $<15 \mathrm{~mm} / \mathrm{hr}$ & 14 & 35 \\
\hline $\begin{array}{l}\text { Above } 10 \\
\text { gm\% }\end{array}$ & 18 & 45 & $\geq 15 \mathrm{~mm} / \mathrm{hr}$ & 26 & 65 \\
\hline Total & $\mathbf{4 0}$ & $\mathbf{1 0 0}$ & Total & $\mathbf{4 0}$ & $\mathbf{1 0 0}$ \\
\hline
\end{tabular}

\section{Association with HIV}

HIV infection was documented in 2 cases, which account for $5 \%$ co infection of HIV in abdominal tuberculosis.

\section{Ascitic fluid examination ( $n=9)$}

Ascitic fluid analysis was done in 9 cases. Ascitic fluid was analysed for cob web, cell count, cell type, protein and sugar. Ascitic fluid with total cell count of 150$4000 / \mu 1$, protein more than $3 \mathrm{gm} / \mathrm{dl}$, predominant lymphocytes $(>70 \%)$ was considered suggestive of tuberculosis. 8 samples $(88.89 \%)$ were suggestive of tuberculosis.

\section{Abdomen X-ray findings}

Seventy two and half percent of cases revealed some or other suggestive findings. Most common finding was dilated bowel loop, observed in 12 cases $(22.5 \%)$, followed by gas under diaphragm and ground glass appearance with $17.5 \%$ each and air fluid levels were seen in $7.5 \%$ cases. abdominal X-ray however was found normal in $27.5 \%$ cases.

\section{Ultrasonography (USG) findings $(n=18)$}

18 patients underwent ultrasound evaluation of abdomen for evaluation and findings suggestive of tuberculosis were found in 7 cases $(38.8 \%)$. Bowel wall thickening, mesenteric lymphadenopathy, free peritoneal fluid or loculated collections on USG were considered suggestive of tuberculosis.

\section{Computerized tomography $(\mathrm{CT})$ findings $(n=11)$}

11 patients with inconclusive USG findings underwent CT scan for further diagnosis. Findings suggestive of abdominal tuberculosis were seen in 5 cases (45.5\%). Bowel wall thickening, matted bowel loops, mesenteric lymphadenopathy, mesenteric thickening, omental thickening on CT scan were considered suggestive of tuberculosis.

\section{According to histopathological findings}

22 patients underwent surgical treatment and specimen was sent for histo pathological examination. Histopathology was suggestive of tuberculosis in $90.9 \%$ cases, revealing granuloma with epitheloid cells, caseation in some and chronic inflammation with lymphocytic infiltration in others. In two cases histopathological finding was not conclusive but were included due to high clinical suspicion.

\section{Modalities of treatment}

It is evident from the above table that majority of patients 
underwent surgical management followed by ATT, 22 cases $(55 \%)$. 18 cases $(45 \%)$ needed only ATT as treatment. Among 18 patients who did not undergo surgical exploration, ascitic type was most common type seen in 9 cases $(50 \%)$, followed by hyperplastic ileocecal mass in 8 cases $(44.4 \%)$ and omental tuberculosis in 1 case $(5.56 \%)$.

Table 8: Distribution according to pathological findings on surgical exploration $(n=22)$.

\begin{tabular}{|lll|}
\hline Site and type & No of cases & Percent \\
\hline $\begin{array}{l}\text { Ileal stricture with } \\
\text { perforation }\end{array}$ & 7 & 31.8 \\
\hline Adhesions & 6 & 27.2 \\
\hline Ileal strictures & 5 & 22.7 \\
\hline $\begin{array}{l}\text { Hyperplastic ileo } \\
\text { cecal mass }\end{array}$ & 3 & 13.6 \\
\hline Colonic stricture & 1 & 4.54 \\
\hline
\end{tabular}

In cases explored surgically, ulcero sclerotic type (ileal stricture with perforation) was the most common pathology seen in 7 cases $(31.8 \%)$ cases, followed by adhesions in 6 cases $(27.2 \%)$, sclerotic (stricture) in 5 cases $(22.7 \%)$, hyperplastic ileocecal mass in 3 cases $(13.6 \%)$ cases and colonic stricture in 1 case $(4.5 \%)$. Ileocecal region was the most common site of involvement with $67.3 \%$ occurrence.

Overall peritoneal tuberculosis was most common, seen in $40 \%$ cases which include, ascitis $(22.5 \%)$, adhesions $(15 \%)$ and omental tuberculosis (2.5\%), followed by ulcerosclerotic gastro intestinal tuberculosis in $32.5 \%$ cases, hyperplastic gastro intestinal tuberculosis in $27.5 \%$. Ileocecal region was the most common site of involvement with $57.5 \%$ occurrence.

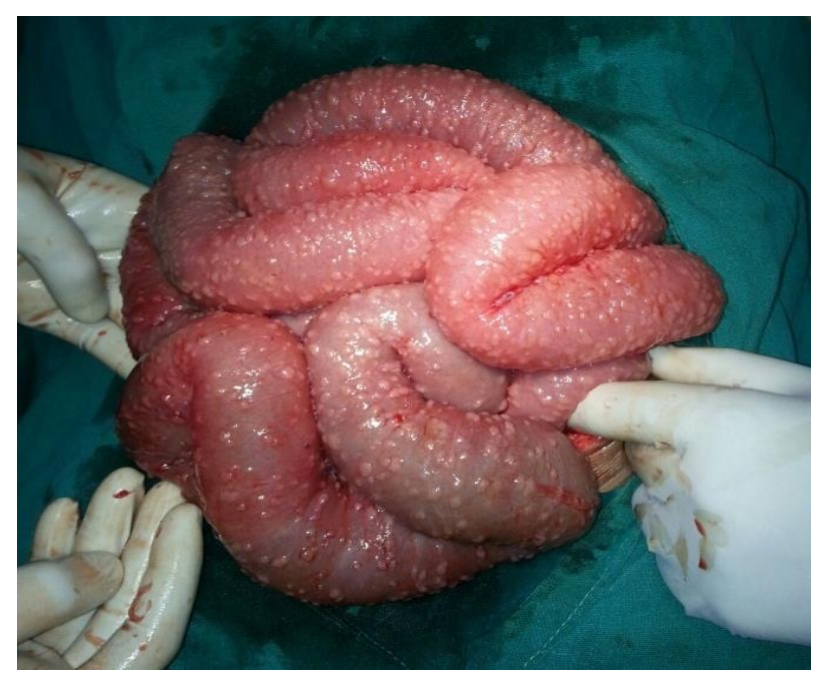

Figure 1: Intra operative image showing typical intestinal miliary lesions characteristic of tuberculosis in a case of SAIO.

\section{Surgical modalities of treatment}

Of 22 patients who underwent surgical management, adhesiolysis was the most common procedure performed $(27.2 \%)$, followed by right hemicolectomy and primary closure of perforation (18.2\%) each. Resection anastomosis and bypass ileo transverse anastomosis was done in $13.6 \%$ cases each. Stricturoplasty and ileostomy alone were done in $4.5 \%$ cases each.

Table 9: Post-operative complications $(n=22)$.

\begin{tabular}{|lll|}
\hline $\begin{array}{l}\text { Postoperative } \\
\text { complication }\end{array}$ & No of cases & Percent \\
\hline $\begin{array}{l}\text { Surgical site infection } \\
\text { (superficial wound } \\
\text { dehiscence) }\end{array}$ & 8 & 36.36 \\
\hline Respiratory infection & 6 & 27.27 \\
\hline Entero cutaneous fistula & 1 & 4.5 \\
\hline
\end{tabular}

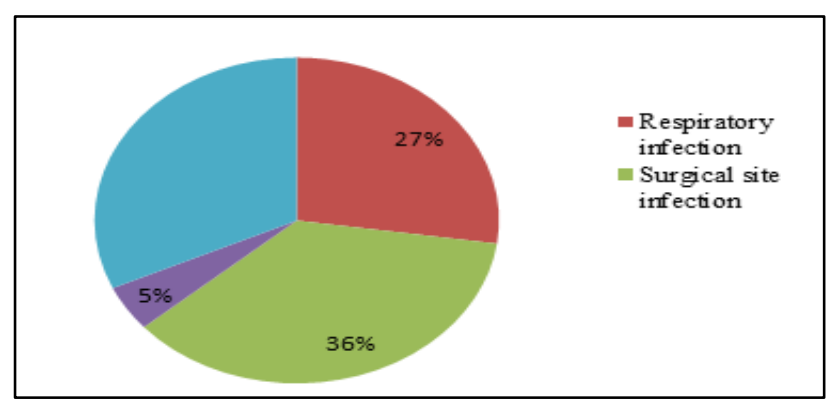

Figure 2: Post-operative complications.

\section{Mortality rate}

During study period, 2 patients succumbed to their illness which included a case of obstruction in which sepsis was the cause and the other being disseminated tuberculosis with ards. Mortality rate was $5 \%$.

\section{DISCUSSION}

\section{Incidence rate}

In present study, incidence of abdominal tuberculosis was found to be $0.5 \%$ of total surgical admissions, which is comparatively less in comparison to findings of similar study carried out by Kapoor in 1998, who in a review of previous Indian studies on abdominal tuberculosis, reported that abdominal tuberculosis accounted for $0.8 \%$ of hospital admissions and $0.7 \%$ of surgical admissions. ${ }^{4}$

The incidence of abdominal tuberculosis is highly variable in different parts of the world. While in Western countries the disease is in declining phase with low incidence, in developing countries it can still be seen in significant proportion. Abdominal tuberculosis may mimic any intra-abdominal disease and can challenge the diagnostic skills. With increased use of diagnostic tools 
like endoscopy, diagnostic laparoscopy, molecular methods like PCR, yield of cases can be improved.

\section{Age distribution}

In present study, most common age group involved was 21-30 years with 15 cases (37.5\%), followed by $31-40$ years $(22.5 \%)$. In age group below 20 years, $41-50$ years, 51-60 years and above 60 years, 4 cases were observed with $10 \%$ occurrence in each. Present study is comparatively similar to study of Govinda Shetty, 2005 who reported $36.8 \%, 21.1 \%$ and $10.5 \%$ incidence among age group 21-30 yrs, 31-40 yrs and 41-50 yrs respectively. ${ }^{5}$ In a retrospective study by Sircar et $\mathrm{al}^{6}$ in 1996, age at presentation was variable with maximum cases in 21 to 40 -year age group (58\% of cases) with a mean age of 32.7 years. ${ }^{6}$ Sharma in 2003 reviewed literature and stated that two thirds are in age group 21$40 .^{7}$ In present study, $59.5 \%$ cases were in age group 2140 yrs which is similar to many other studies in literature reviewed. The present study however clearly indicates that no age is immune to abdominal tuberculosis.

\section{Sex distribution}

In present study, majority of patients were males $(65 \%)$, while $35 \%$ were females which is comparable with that reported by Amit Agarwal in 2007, who reported an incidence of $62.6 \%$ in males and $37.3 \%$ in females. ${ }^{8}$ In a recent study, Seema Awasthi et al 2015 also reported male preponderance with $58 \%$ involvement. ${ }^{9}$ Thus it can be safely said that the results of current study are consistent with previous study, however other studies like that of Das and Shukla et al, 1976 and Arunima M et al, 2014 have reported maximum occurrence in females with $72 \%$ and $61.5 \%$ respectively. ${ }^{10,11}$

\section{Socio economic status (SES)}

In present study, maximum cases were seen in low socio economic status with $85 \%$ in BPL strata. This co relates with findings of previous studies like Arunima $\mathrm{M}$ et al 2014 who reported 92\% occurrence in low SES respectively. ${ }^{11}$ People of low and middle socioeconomic status are more frequent victims of abdominal tuberculosis, but there seems to be no significant differences in its prevalence in the rural as against the urban population. Malnutrition, poor housing conditions, overcrowding which are offshoots of poor socio economic status are known to foster tuberculosis.

\section{Symptoms}

Presenting symptoms in abdominal tuberculosis vary widely and are non specific. It may mimic any intraabdominal disease and can challenge the diagnostic skills. In present study pain abdomen was the most common symptom, seen in $82.5 \%$ cases. In a similar study by Bhansali in 1978 and Govinda Shetty in 2005, pain was the most common symptom observed in $100 \%$ and $89.5 \%$ cases respectively. ${ }^{12,5}$ Next most common symptom in present study was abdominal distension, seen in $62.5 \%$ of cases, which is similar to previous studies. In study by Govinda Shetty in 2005, 65.8\% cases had distension of abdomen. Bowel disturbance was observed in $52.5 \%$ cases, which is comparatively similar to previous studies. Constitutional symptoms like fever and weight loss were seen in $47.5 \%$ and $50 \%$ cases respectively. Vomiting was observed in $20 \%$ cases and lump in abdomen was observed in $15 \%$ cases.

Pain abdomen was the complaint in most cases. In cases of ascitis, subacte and acute obstruction and peritonitis, abdominal distension was the presenting complaint. Bowel disturbance was seen in most cases of right iliac fossa mass, which can be explained by the hypertrophic tuberculosis, seen among exposed population with increased resistance to the organism.

\section{Association with pulmonary tuberculosis}

In present study $22.5 \%$ patients had pulmonary tuberculosis with active pulmonary tuberculosis in 5\% and past history of pulmonary tuberculosis in $17.5 \%$. The present study is significantly comparable with that of Bhansali, 1978. ${ }^{12}$ TB of the gastrointestinal tract is the sixth most frequent form of extra-pulmonary site, after lymphatic, genitourinary, bone and joint, miliary and meningeal tuberculosis. Autopsies conducted on patients with pulmonary tuberculosis before the era of effective antitubercular drugs revealed intestinal involvement in $55-90 \%$ cases, with the frequency related to the extent of pulmonary involvement.

\section{Signs}

In present study distension of abdomen was the most common sign seen in $75 \%$ cases, followed by tenderness (57.5\%), ascitis (42.5\%), lump in abdomen (17.5\%), guarding or rigidity $(7.5 \%)$ and visible peristalsis $(2.5 \%)$. Distension of abdomen was the most common sign seen in cases of SAIO, AIO, perforation peritonitis and ascitis. Abdominal tenderness was present in all cases of peritonitis and most cases of SAIO and AIO and few cases of asctis. Lump in abdomen was noted in $17.5 \%$ cases. Abdominal tenderness and distension were the predominant signs in present study, which is similar to study by Das et al, 1972 and Govinda Shetty, 2005..$^{10,5}$ Abdominal signs in tuberculosis are non specific. Presentation of abdominal tuberculosis depends on virulence of bacteria, host resistance, organ involved and time of presentation.

\section{Hemoglobin $(\mathrm{Hb})$ and ESR}

In present study $55 \%$ were anemic and ESR was raised in $65 \%$ cases. In general the results of hematological and biochemical investigations will indicate a chronic inflammatory process. The blood picture will show normocytic, normochromic type of anaemia. ESR is a 
non specific marker of chronic inflammation which is raised in many diseases as well.

\section{Association with HIV}

In present study $5 \%$ cases were associated with HIV infection, compared to $7.9 \%$ of Govinda Shetty study in 2005 . $^{5}$ HIV infection is diagnosed by spot test and needs to be confirmed with western blot or repeat ELISA and serology may be negative during window period of HIV infection, explaining the differences. Both the incidence and severity of abdominal tuberculosis are expected to increase with increasing incidence of HIV infection in India.

\section{Ascitic fluid analysis}

In 9 cases of ascitis, ascitic fluid analysis was carried out and 8 samples were suggestive of tubercular ascitis with ascitic fluid protein level greater than $3 \mathrm{~g} / \mathrm{dl}(88.88 \%)$, cell count more than $200 / \mathrm{mm} 3$ with predominant lymphocytes $(>70 \%)$. In a similar study conducted by Amit Agarwal in 2006, ascitic fluid examination was suggestive of tuberculosis in $62.5 \%$ cases. $^{8}$ With use of ADA estimation, more cases are being diagnosed recently with ease.

\section{Radiological evaluation}

$X$-ray abdomen: Most common finding was dilated bowel loop, observed in 12 cases (30\%), suggestive of sub-acute obstruction, followed by gas under diaphragm suggesting perforation and ground glass appearance suggesting ascitis in 7 cases $(17.5 \%)$ each and air fluid levels were seen in 3 cases(7.5\%), suggestive of bowel obstruction. All 7 cases of peritonitis revealed pneumoperitoneum on abdominal X-ray, suggesting perforation. In 11 cases, abdominal X-ray did not reveal any significant finding, which included 3 cases of ascitis. In a similar study by Amit Agarwal in 2006, dilated bowel loops were seen in $33.8 \%$ cases, air fluid levels in $2.8 \%$ cases and ground glass appearance was seen in $15.4 \%$ cases. $^{8}$

$X$-ray chest: On chest X-ray, lesion suggestive of tuberculosis was present in 7 cases, which included 2 cases of active pulmonary tuberculosis. Chest x-ray was suggestive of fibrotic lesion in 4 cases, bilateral effusion in 1 case and cavitatory lesion in 1case. Chest $\mathrm{x}$-ray was suggestive of miliary tuberculosis in 1 case, revealing miliary mottling.

Ultrasonography (USG): A total of 18 patients underwent ultrasonographic evaluation, in which findings suggestive of tuberculosis like bowel thickening, mesenteric lymphadenopathy, matted bowel loops and ascitis was seen in 7 cases $(38.8 \%)$. In 11 cases findings were inconclusive.

$C T$ : 11 cases in which USG was inconclusive were further evaluated with $\mathrm{CT}$ abdomen and findings suggestive of abdominal tuberculosis like peritoneal thickening, nodularity and retroperitoneal lymph nodes along with mesenteric lymphadenopathy and bowel thickening were seen in 5 cases $(45.5 \%)$. In 6 cases findings were inconclusive. Thus concluding that even CT scan of abdomen is also not $100 \%$ diagnostic.

\section{Various sites and type of lesion}

In present study, peritoneal tuberculosis was most common, seen in $40 \%$ cases which include, ascitis $(22.5 \%)$, adhesions $(15 \%)$ and omental tuberculosis $(2.5 \%)$, followed by ulcerosclerotic gastro intestinal tuberculosis in $32.5 \%$ cases, hyperplastic gastro intestinal tuberculosis in $27.5 \%$. Ileocecal region was the most common site of involvement with $57.5 \%$ occurrence. In a similar study by Govinda Shetty in 2005, hyperplastic tuberculosis was seen in $18.3 \%$ cases, sclerotic type in $36 \%$, ascitic type in $44.7 \%$ and ulcerative in $8 \%$ cases. $^{5}$ Differences as seen in other studies is probably due to the fact that the pathological changes of abdominal tuberculosis in a host depend on virulence of bacteria, host resistance, organ involved and time of presentation. Although, abdominal tuberculosis is seen less in visceral organs, none are immune to it.

\section{Modalities of treatment}

22 patients underwent surgical treatment. 18 patients were treated with anti-tubercular chemotherapy alone. All 6 patients with adhesions underwent adhesiolysis. 4 cases of ileal perforation with passable stricture underwent primary closure of perforation with or without diversion ileostomy. 3 cases of ileal stricture with perforation underwent resection with 1 requiring resection alone, 1 requiring end to end anastomosis with diversion ileostomy and in 1 case end ileostomy was created. A case of colonic stricture was managed with right hemicolectomy (RHC). 3 cases of SAIO on exploration were found to have matted hyperplastic ileocecal lump, in which RHC was done in 2 cases and 1 case was managed by creating a proximal loop ileostomy alone, due to poor general condition of the patient. 5 cases of ileal stricture were identified on exploration among which, a case of ileocecal junction stricture underwent RHC, 3 underwent bypass procedure with ileo transverse anastomosis and 1 case was managed with stricturoplasty. Serosal surface of intestines was studded with tubercles in 3 cases. Ileostomy was created in 11 cases total. Biopsies were taken for histopathological examination in all cases explored. All the patients were put on ATT for six months in accordance with recent RNTCP guidelines.

\section{Post-operative complications}

10 patients developed post-operative complications among 22 operated. $44.4 \%$ complication rate was noted. Surgical site infection (superficial wound dehiscence) was the most common complication documented in 8 cases $(36.3 \%)$, followed by respiratory infection in 6 
cases $(27.2 \%)$. Enterocutaneous fistula was documented in 1 case $(4.5 \%)$. 6 cases of SSI recovered with local wound dressings. 4 cases of respiratory infection recovered with antibiotics and chest physiotherapy. 2 cases of SSI with respiratory infection succumbed to their illness with cause being sepsis in one and disseminated tuberculosis with ARDS in other. 1 patient of entero cutaneous fistula was managed conservatively with TPN and the patient was lost for follow up, after being discharged on request. In a similar by Arunima M, et al in 2014, respiratory infection was the most common complication seen in $15 \%$ cases, followed by wound infection in $10 \%$, enterocutaneous fistula in $4.6 \%$. $^{11}$

\section{Prognosis}

22 patients completed full course of ATT and clinical improvement was seen, while 18 patients are on ATT and are symptomatically better. None of the patients had recurrence during study. 2 cases were lost for follow up during study.

\section{Mortality}

2 patients succumbed to their illness during treatment, which included a case of obstruction in which sepsis was the cause and the other being disseminated tuberculosis with ARDS. Mortality rate was 5\%, which is comparatively similar to a study by Arunima M, et al in 2014. ${ }^{11}$ Ignorance associated with low socio economic group, late presentation and other co morbid conditions were the factors contributing to mortality in present study.

\section{CONCLUSION}

Abdominal tuberculosis is predominantly seen in low socio economic strata. It commonly affects the adults in their 3rd and 4th decades. All patients with tuberculosis should be screened for HIV infection as the Tubercular infection in immunocompromised AIDS patient is on the rise. Ulcero sclerotic type (ileal stricture with perforation) was the most common pathology. Anti-tuberculosis therapy is still the treatment of choice in abdominal tuberculosis and surgery is only indicated in various complication of abdominal tuberculosis.

Funding: No funding sources

Conflict of interest: None declared

Ethical approval: The study was approved by the institutional ethics committee

\section{REFERENCES}

1. Rathi PM, Amarapurakar DN, Parikh SS, Joshi J, Koppikar GV, Amarapurkar AD, et al. Impact of human immunodeficiency virus infection on abdominal tuberculosis in western India. J Clin Gastroenterol. 1997;24:43-8.

2. Kapoor VK. Abdominal tuberculosis. Postgrad Med J. 1998;74:459-6.

3. Balasubramanian R, Nagarajan M, Balambal R, Tripathy SP, Sundararaman R, Venkatesan P. Randomised controlled clinical trial of short course chemotherapy in abdominal tuberculosis: a five-year report. Int J Tuberc Lung Dis. 1997;1:44-51.

4. Kapoor VK. Abdominal tuberculosis: the Indian contribution. Indian J Gastroenterol. 1998;17:141-7.

5. Setty G. Clinico Pathological Study of Abdominal Tuberculosis. Bangalore: RGUHS; 2006.

6. Sircar S, Taneja V A, Kansara U. epidemiology and clinical presentation of abdominal tuberculosis: a retrospective study. J Indian Med Assoc. 1996;94(9):342-4.

7. Sharma MP, Bhatia V. Abdominal tuberculosis. Indian J Med Res. 2004;120:305-15.

8. Amit Agrawal. Clinicopathological study of Abdominal Tuberculosis. Rewa. 2006.

9. Awasthi S, Manoj S, Faiyaz A, Ashutosh K, Shyamoli D. Abdominal tuberculosis: A diagnostic dilemma. JCDR. 2015;9(5):1-3.

10. Das P, Shukla H S. Clinical diagnosis of abdominal tuberculosis. Br J Surg. 1976;63(12):941-6.

11. Arunima M, Ramprasad D, Ujjwal Bhattacharya. Abdominal tuberculosis with an acute abdomen: our clinical experience. J Clin Diagn Res. 2014;8(7):79.

12. Bhansali SK. Abdominal tuberculosis. Experiences with 300 cases. Am J Gastroenterol. 1977;67:32437.

Cite this article as: Urabinahatti KA, Singh AK, Nayak A, Gupta R, Jain M, Dubey C, et al. Abdominal tuberculosis: an epidemiological profile and management of 40 cases in a tertiary set up. Int Surg J 2016;3:1502-8. 